\title{
Sporulation in Bacillus subtilis. Characterization of Oligosporogenous Mutants and Comparison of Their Phenotypes with Those of Asporogenous Mutants
}

\author{
By J. G. COOTE \\ Microbiology Unit, Department of Biochemistry, University of Oxford, \\ South Parks Road, Oxford, $O X$ I $3 Q U$
}

(Accepted for publication 23 December I97I)

SUMMARY

\begin{abstract}
An investigation was undertaken to determine to what extent the properties of oligosporogenous (Osp) mutants allow them to be considered as a separate class of sporulation mutant, distinct from asporogenous $\left(\mathrm{Sp}^{-}\right)$mutants. Of thirty Osp mutants examined, seventeen at least had a phenotype which had previously been identified with a $\mathrm{Sp}^{-}$mutant. The majority of cells in an Osp culture either reached a particular stage in the sporulation process and then stopped, or in some cases went on to produce aberrant forms. Some of these aberrant forms have their counterparts in $\mathrm{Sp}^{-}$mutants described by other authors, but some present new features. The morphological and biochemical sequences were linked so that if the majority of cells were blocked at a certain stage, then the biochemical sequence stopped accordingly. The general similarity in behaviour between the two types of mutant is consistent with the assumption that at least some of the Osp mutants have leaky mutations in genes where mutation can also give rise to $\mathrm{Sp}^{-}$phenotypes. Evidence is presented to suggest that the ability of a cell of an Osp mutant to overcome its block, and so go on to form a spore, is a chance event when that stage in the process is reached. A mutant has been obtained in which the spores are octanolresistant yet contain no measurable dipicolinate. In several other mutants the spores contained well-developed coat layers, but the cortex was poorly formed or completely missing.
\end{abstract}

\section{INTRODUCTION}

Sporulation mutants of bacilli may be divided into two types. They may be completely asporogenous ( $\left.\mathrm{Sp}^{-}\right)$and incapable of producing any heat-resistant spores. Alternatively they may be oligosporogenous (Osp) and characterized by subnormal production of heatresistant spores, under conditions that lead to almost complete sporulation in the wild-type (Schaeffer \& Ionesco, 1960). All degrees of sporulation may be found in Osp mutants, from one spore in five cells to one in $10^{8}$, but for any one mutant the level of sporulation under defined conditions is fixed. It may, however, vary somewhat depending on the composition of the growth medium (Aubert \& Millet, 1961). If a heat-resistant spore from an Osp culture is allowed to germinate and grow out it gives rise to a population of cells that will again sporulate at the same low frequency. This is the defining characteristic of the Osp phenotype (Schaeffer, Ionesco, Ryter \& Balassa, 1965) and distinguishes clearly between Osp populations and $\mathrm{Sp}^{-}$populations containing $\mathrm{Sp}^{+}$revertants. A spore from the latter will produce a population that sporulates at a high frequency.

From what is now known (Kornberg, Spudich, Nelson \& Deutscher, I968; Schaeffer, 1969; Mandelstam, 1969; Hanson, Peterson \& Yousten, 1970) it is clear that a sporulating cell has to carry out some syntheses that are specifically connected with sporulation, but at

Vol. 70, No. 3, was issued 30 May 1972 
the same time it has to synthesize many enzymes that are apparently identical in the spore and in the vegetative cell (Kornberg et al. I968). For both sets of reactions the normal vegetative machinery of the cell has to be maintained and in particular there is a need for an efficient energy-generating system. It is therefore not surprising that damage to an enzyme of the tricarboxylic acid cycle or to the cytochrome system should impair the ability to sporulate and Osp mutants of this type have been described (Hanson, Blicharska \& Szulmajster, 1964; Bott \& Davidoff-Abelson, 1966; Fortnagel \& Freese, 1968).

For this reason, in the work described here, potential Osp mutants were screened to exclude, as far as was possible, those damaged in normal vegetative growth. Oligosporogenous mutants have been variously looked upon as having leaky mutations in structural genes (Schaeffer et al. 1965) or as a separate class of regulatory mutants (Schaeffer et al. 1965; Hanson et al. 1970). Mutants of the former type would be expected to have a Sp- counterpart which behaved morphologically and biochemically in a similar manner. Mutants of the latter type would be expected to have characteristics not associated with $\mathrm{Sp}^{-}$mutants. Both $\mathrm{Sp}^{-}$and Osp mutants of Bacillus subtilis blocked at defined stages in the morphological sequence of sporulation have been described (Ryter, Schaeffer \& Ionesco, 1966; Balassa \& Yamamoto, 1970; Waites et al. 1970). The latter two groups of workers have in addition attempted to correlate certain biochemical properties with the cytological appearance of the mutants. Waites et al. (1970) considered only Sp- mutants while Balassa \& Yamamoto (I970) described Osp mutants incidentally together with $\mathrm{Sp}^{-}$mutants.

An investigation of specifically Osp mutants was undertaken with a number of ends in view: (i) to establish to what extent the phenotypic blocks of the Osp mutants had previously been identified with a $\mathrm{Sp}^{-}$character; (ii) to decide whether each Osp mutant has a majority of cells which get to one stage in the sporulation process and then stop, or whether some mutants have increasing difficulty in overcoming each stage so that only a few cells eventually complete the process - this latter type of behaviour has been reported for some mutants (Balassa \& Yamamoto, I970); (iii) to determine whether the correlation of biochemical events with morphological changes that is found in the wild-type and in $\mathrm{Sp}$ - mutants (Waites et al. 1970) is maintained in Osp mutants; (iv) to determine whether the genes producing the Osp phenotype are situated in the same regions of the genome as are the Sp- mutations. A genetic investigation of the mutants described here is reported in an accompanying paper (Coote, I972). It is concluded provisionally that some Osp mutants have leaky mutations in genes where mutation can also produce a $\mathrm{Sp}^{-}$phenotype.

\section{METHODS}

Organism. Bacillus subtilis MARBURG I68 was used which, although it is an auxotroph requiring indole or tryptophan, forms spores normally and is therefore referred to as the wild-type.

Media. Glutamate minimal medium was the 'resuspension' medium as described by Sterlini \& Mandelstam (I969), but without the excess $\mathrm{Mg}^{2+}$ added. When the L-glutamate in this medium was replaced by L-lactate $(0.2 \%)$ or supplemented with either L-lactate or D-glucose $(0.2 \%)$ the media are referred to as lactate minimal, lactate-glutamate minimal and glucose-glutamate minimal respectively. These media were used as such or were solidified with I \% agar (Davis Gelatine Itd, Warwick, Warwickshire).

Sporulation. The organisms were grown with shaking at $37^{\circ} \mathrm{C}$ in a medium containing hydrolysed casein and inorganic ions (Sterlini \& Mandelstam, I969). When the cells were growing exponentially and the bacterial concentration had reached $0.25 \mathrm{mg}$ dry wt $/ \mathrm{ml}$, the 
culture was centrifuged and the cells transferred at the same density to a resuspension medium containing L-glutamate and inorganic ions with $0.04 \mathrm{M}-\mathrm{Mg}^{2 \div}$ (Sterlini \& Mandelstam, 1969). Cells shaking in this medium at $37^{\circ} \mathrm{C}$ gave a yield in the wild-type of about $80 \%$ refractile spores in 7 to $8 \mathrm{~h}$.

Growth and spore incidence. Growth was measured spectrophotometrically using a calibration curve relating extinction at $600 \mathrm{~nm}$ to bacterial dry weight. Refractile spores were counted in the phase-contrast microscope.

Isolation of mutants. Mutant strains were derived by treatment of the wild-type with either $N$-methyl- $N^{\prime}$-nitro- $N$-nitrosoguanidine (NTG) and were designated z and DG mutants, or ethylmethanesulphonate (EMS) and were designated $\mathrm{P}, \mathrm{X}, \mathrm{Y}$ or $\mathrm{W}$ mutants. Cells in exponential growth (approximately $4 \times 10^{9} / \mathrm{ml}$ ) were centrifuged, resuspended in glutamate minimal medium $(2.5 \mathrm{ml})$ and shaken at $37{ }^{\circ} \mathrm{C}$. NTG (final concn $250 \mu \mathrm{g} / \mathrm{ml}$ ) or EMS (O. I ml) was added and samples withdrawn at 5 and 10 min intervals. The bacteria were washed and inoculated into $50 \mathrm{ml}$ volumes of hydrolysed casein medium. The flasks were shaken overnight at $37^{\circ} \mathrm{C}$, diluted $10^{5}$ times and $0.2 \mathrm{ml}$ portions plated on lactate-glutamate minimal agar. This medium allowed maximum production of the brown pigment associated with sporulation in this strain (Iichinska, 1960; Schaeffer \& Ionesco, 1960) after incubation for 2 to 3 days at $37^{\circ} \mathrm{C}$. Both Osp and $\mathrm{Sp}^{-}$mutants produced translucent, white or light brown colonies under these conditions.

Screening of mutants. Colonies were picked and streaked in turn on to lactate-glutamate minimal agar and nutrient agar (Oxoid Ltd, London). After incubation at $37^{\circ} \mathrm{C}$, colonies that grew badly on the minimal agar were rejected, as also were colonies showing a better degree of sporulation on the nutrient agar than on the minimal agar. This was based on the supposition that the rich medium was permitting better sporulation because it was supplying a nutrient needed for sporulation which bacteria with normal vegetative metabolism could have synthesized. The remaining colonies were streaked on to lactate minimal agar and those showing poorer growth than the wild-type were again rejected because, for growth on lactate, Bacillus subtilis requires a fully functional tricarboxylic acid cycle (Hanson \& Mackechnie, I969). Finally the growth rate of each mutant in glucose-glutamate minimal medium was compared with that of the wild-type, and only mutants that had a growth rate equal to that of the wild-type were retained.

Oligosporogenous mutants were distinguished from $\mathrm{Sp}^{-}$strains as follows. A loopful of bacteria from an agar plate was transferred to sterile glutamate minimal medium, thoroughly dispersed and the $E_{600}$ noted. A portion of this suspension $(0.1 \mathrm{ml})$ was added to $0.9 \mathrm{ml}$ sterile glutamate minimal medium, heated at $85^{\circ} \mathrm{C}$ for $10 \mathrm{~min}$ to kill vegetative cells and $0.1 \mathrm{ml}$ plated on nutrient agar to determine the incidence of heat-resistant spores. If the culture was in a resuspension medium then $0.1 \mathrm{ml}$ was removed directly into $0.9 \mathrm{ml}$ sterile glutamate minimal medium and heated. Under these conditions suspensions of Sp- mutants were sterile while those of Osp mutants produced colonies depending on the incidence of heat-resistant spores. After incubation at $37^{\circ} \mathrm{C}$ for 2 days single colonies were picked, allowed to sporulate and the treatment repeated. If the incidence of heat resistance was the same as in the original isolate the mutant was taken for further investigation.

Electron microscopy. Mutant strains initiated to sporulation in the resuspension medium were sampled after $7 \mathrm{~h}$, fixed and thin sections prepared as described by Kay \& Warren (I968). Only complete longitudinal sections through cells were assessed for their stage of development.

Terminology and abbreviations. The number of hours after transfer of cells from growth medium to resuspension medium is indicated by $t_{0}, t_{1}$, etc. Stages $\mathrm{O}$ to VI are the recognized 
cytological stages of spore formation (Ryter, I965). Each of them is found to predominate at a defined time after the initiation of the process $\left(t_{0}\right)$.

Qualitative assay for exoprotease. Samples of supernatants from resuspension experiments were added to albumin agar (Mandelstam \& Waites, 1968). Proteolytic activity produced zones of clearing after $48 \mathrm{~h}$ incubation at $37^{\circ} \mathrm{C}$.

Enzyme assays. Alkaline phosphatase and glucose dehydrogenase were determined in samples from the resuspension medium as described by Warren (I968). One unit of enzyme is defined as the amount catalysing the reaction of I nmol of substrate/min and specific activities are expressed either as units/mg protein or as units $/ \mathrm{ml}$ of culture. Soluble protein was determined by the method of Lowry, Rosebrough, Farr \& Randall (195I).

Assay of 2,6-dipicolinic acid (DPA). Samples (I50 ml) were taken from the resuspension medium and the DPA in the cells determined as described by Warren (I968). DPA in the supernatants was assayed as described by Waites et al. (I970).

Assay of octanol resistance. The bacterial suspension ( $\mathrm{I} \mathrm{ml}$ ) was shaken vigorously with $0.01 \mathrm{ml}$ of octan-I-ol for $\mathrm{I}$ min and dilutions plated on nutrient agar to determine the viable count.

\section{RESULTS}

Effect of carbon source on the incidence of heat-resistant spores. The Osp strains were allowed to grow and sporulate on lactate minimal and glucose-glutamate minimal agar. Although the incidence of spore formation was reproducibly the same, using any one medium, the mutants showed some variation in spore formation when the carbon source was changed. In some instances the lactate minimal medium promoted better spore formation, but with other mutants the reverse was true. Mutants z3I and z24 sporulated to approximately I \% and $0.4 \%$ respectively of the wild-type level on lactate minimal agar. The corresponding values on glucose-glutamate minimal agar were 0.25 and $0.08 \%$. With mutants $\mathrm{zIOA}$ and YI 3 the values were $0 . \mathrm{I}$ and $0.03 \%$ on the first medium and I and $0.4 \%$ on the second. These variations were, however, the exception and most of the mutants examined showed smaller differences.

Morphology of oligosporogenous mutants. This is considered in relation to normal spore development (Fig. I). The end of each stage is illustrated, and the data of Dawes, Kay \& Mandelstam (1969) have been used to give the times $\left(t_{1}, t_{2}\right.$, etc.) at which the end of each stage is reached. This is an idealized representation because the cultures are unsynchronized and the appearance of any one stage is spread out over a period of an hour or more.

Only those cells in a culture of an Osp mutant which do not form mature spores are considered here. These cells will be a major but variable fraction, depending on the mutant concerned (see Table I). In many instances the mutation resulted in normal development to a defined point in the sporulation process, whereas in others development diverged to produce aberrant forms some of which are schematically depicted in Fig. I.

Stage $O$ and $I$ mutants. These are mutants blocked before spore septum formation (stage II). Like most other workers I have found it difficult to distinguish unequivocally between stages $\mathrm{O}$ and $\mathrm{I}$; therefore mutants of these types have been grouped together. In resuspension medium the cells of mutants Z29, ZI2, Z3I, PIO and PI2, not forming spores, divided to give short and almost square cells. In addition the cells of $\mathrm{Z} 29$ formed abnormally thick walls which gave rise to multiseptate filaments (Fig. $2 a$ ). Mutant YI 3 produced long elongated cells in resuspension medium. With both these mutant types when spores were observable the small proportion of cells containing them appeared normal in length and so did the cells when growing vegetatively in a rich medium. All the cells of mutants P2, PI 3 and PI9, 


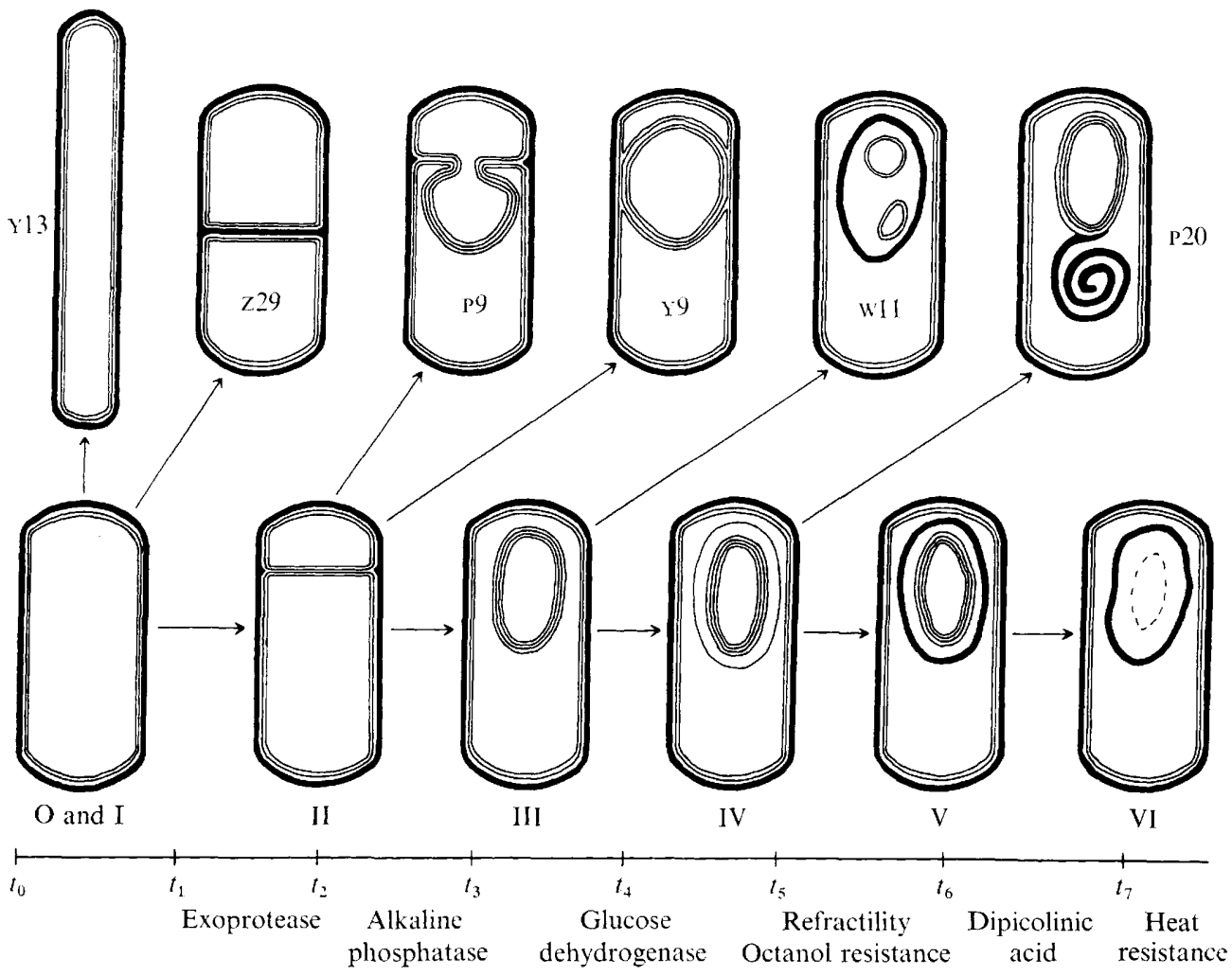

Fig. I. Schematic representation of the six stages of sporulation (Roman numerals). For an illustration of intermediate steps, particularly the transition from stage II to III, see Murrell (I967). The approximate times at which the end of each stage is reached are indicated by $t_{0}, t_{1}$, etc. The marker events referred to in the text are included at roughly the times they achieve $50 \%$ of their maximum values. Some of the aberrant forms developed by mutants are shown above the normal developmental sequence (see also Fig. 2 to 4 ).

including those not forming spores, appeared normal in length and showed no characteristics of sporulating cells. Asporogenous mutants similar to these Osp mutants have been reported (Ryter et al. 1966; Balassa \& Yamamoto, 1970; Waites et al. 1970).

Stage II mutants. These are mutants blocked at the stage of spore septum formation. Mutant z3 laid down a complete septum at one end of the cell, but further development did not occur although the occasional cell was seen where the membrane had begun to protrude into the cytoplasm of the mother cell. Mutants PI4 and PI 8 developed septa at both ends of the cell and laid down cell wall material between the double membranes of each septum. The central portion of the cells eventually lysed and released the two polar 'pygmy' cells. These two types of Osp mutants are similar to $\mathrm{Sp}^{-}$mutants which have been described (Ryter et al. 1966; Waites et al. 1970). Mutant P9 formed a spore septum in the normal way at one end of the cell, but the bulging double membrane of the developing protoplast continued to grow while remaining attached to the original cell wall invaginations (Fig. $2 b$ ).

Stage III mutants. These are mutants in which most of the cells have stopped at the complete spore protoplast stage and which then fail to initiate cortex or coat formation. Mutants YIO, X3 and WI 2 were able to reach the stage where a detached prespore was formed within the cell. $\mathrm{x} 3$ tended to lyse soon after this, leaving a cell envelope containing only membrane. 

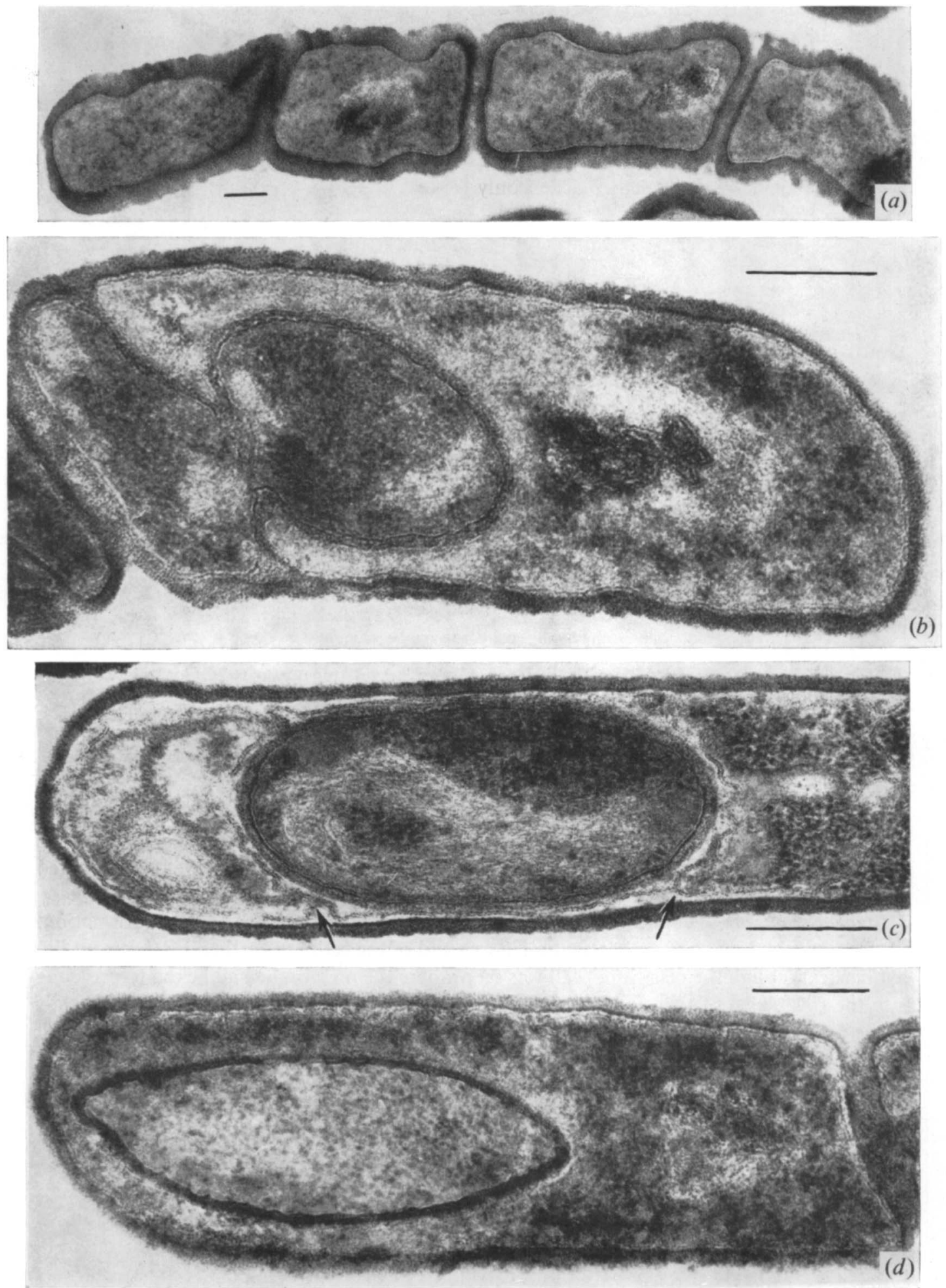
Very similar $\mathrm{Sp}^{-}$mutants have been previously described (Ryter et al. I966; Waites et al. 1970). Y9 and $\mathrm{P} 4$ were very similar mutants and after $7 \mathrm{~h}$ resuspension most of the cells had formed protoplasts and had begun to lyse. In the lysed cells the outer spore membrane appeared to be joined to and continuous with the cytoplasmic membrane of the mother cell. Completely detached prespores were not formed (Fig. 2c).

Stage IV mutants. These are mutants which initiated cortex formation, but in which no coat material was laid down. Mutants z5, Z33A, z28, Z24 and x8 all showed a similar morphology. Most of the cells reached only the first stage of cortex formation, seen as a dark staining area in electron micrographs between the twin membranes of the prespore (Fig. $2 d$ ). After about $\mathrm{I} 5 \mathrm{~h}$ in resuspension the mother cells lysed and released these small unfinished prespores (which were quite stable) into the medium. Mutant P7 had an almost fully developed cortex which included the outer cortical layer seen as a very light staining area in electron micrographs (Fig. 3a). Again, these Osp mutants resemble Sp- mutants which have been described (Ryter et al. 1966; Balassa \& Yamamoto, 1970; Waites et al. I970).

Stage $V$ mutants. These are mutants in which the majority of the cells could form spores, up to the stage at which they possessed both cortex and coat layers, but were unable to complete the maturation process and produce heat-resistant spores. The normal decrease in electron density of the spore core which occurs in the wild-type during maturation (Kay \& Warren, 1968) did not occur in these mutants and much detail of the spore core showed up well in electron micrographs. The cortex of mutant wio had an unusual striated appearance (Fig. $3 b$ ) and the development of the coat layers appeared to be complete only at the poles of the spore. The cortex of mutant ZIOA appeared quite dark in photographs, but in this instance coat development occurred all round the spore and not merely at the poles. Similarly, the cortex of mutant DG47 seemed to be incompletely developed (Fig. $3 \mathrm{c}$ ) although the coats again surrounded the spore. Asporogenous mutants with these characteristics do not seem to have been described.

Abnormal late mutants. In mutant w5 the spores had well-developed coat layers, but the cortex was almost entirely missing (Fig. 4a). A similar $\mathrm{Sp}^{-}$variant has been described (Balassa \& Yamamoto, I970). The cells of mutant WI I not going on to form mature spores developed in an atypical manner and seemed to reveal compartmented protoplasts surrounded normally by the coat layers (Fig. $4 b$ ). The cortex appeared to be missing; a Spstrain with these characteristics has not been described. In mutant P2O, spores developed normally up to the initial stage of cortex formation. The coat material seemed then to be synthesized and deposited in concentric layers in the cytoplasm of the mother cell rather than around the spore protoplast (Fig. $4 c$ ). When these cells were viewed in the light microscope there appeared to be two feebly refractile bodies in each cell. A Sp- mutant with a similar morphology has been reported (P. Piggot \& D. A. Wood, personal communication).

Mutant with retarded sporulation rate. In addition to these mutants one was isolated which appeared to be Osp if sampled at $t_{7}$ after resuspension (producing only two in $10^{3}$ heatresistant units), but on continued resuspension it achieved a level of heat resistance similar to the wild-type by about $t_{15}$. Examination of the cells at $t_{7}$ in the electron microscope

Fig. 2. (a) Mutant z29. A filament of cells showing abnormally thick walls and close division septa. (b) Mutant P9. The growing double membrane of the spore septum has remained attached to the original mother cell wall invaginations. (c) Mutant Y9. A completely free protoplast appears not to have been formed because the outer spore membrane is continuous with the mother cell membrane (arrowed). (d) Mutant Z28. Development has stopped at the first stage of cortex formation, the primordial germ cell wall. This is seen as an electron-dense band between the spore membranes. Electron micrographs of oligosporogenous mutants of Bacillus subtilis $\mathrm{I} 68$, showing cells which did not form mature spores. Bar markers represent $0.2 \mu \mathrm{m}$. 

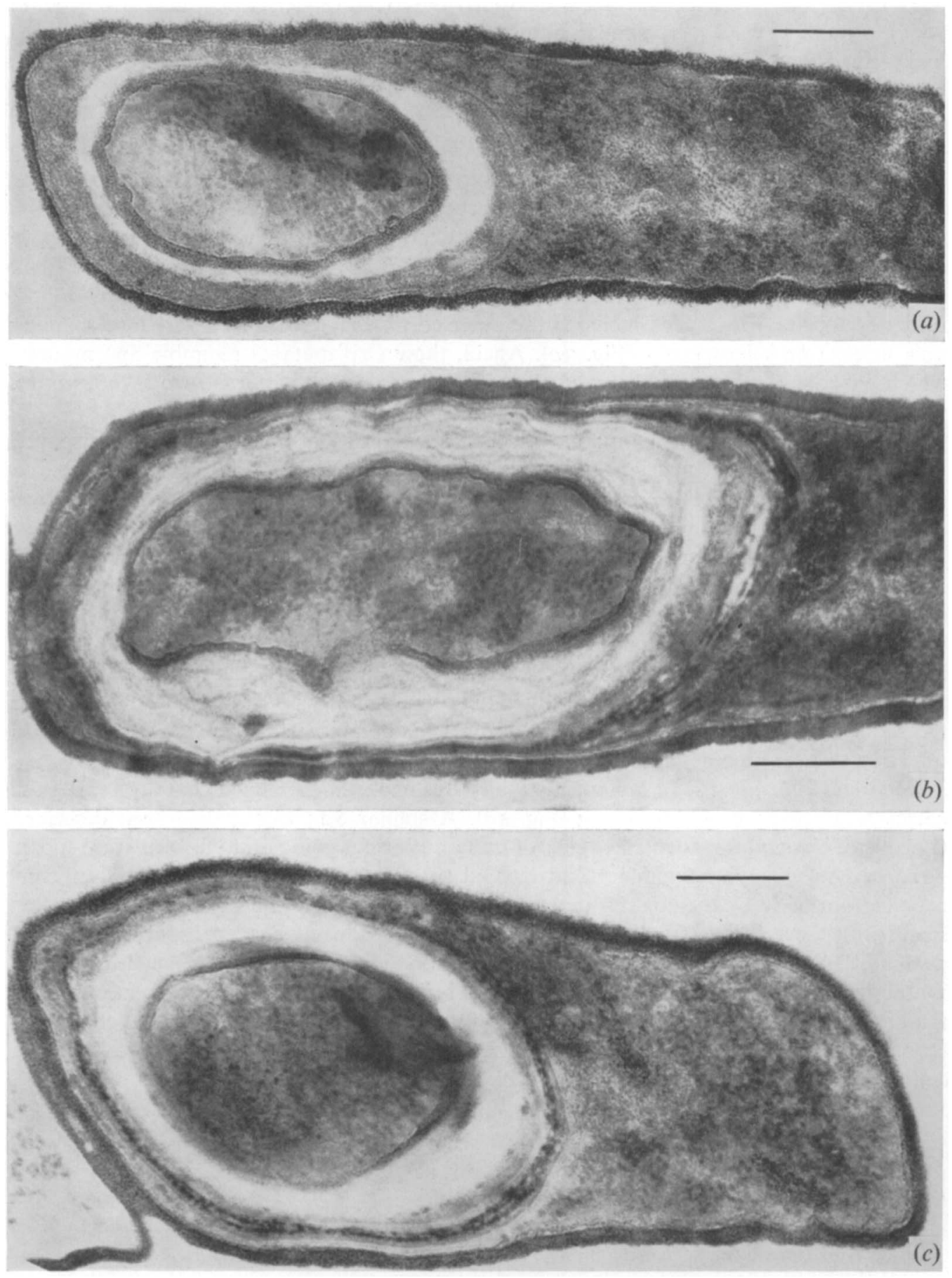

Fig. 3. (a) Mutant P7. Cortex development is almost complete, but coat formation is arrested at an early stage. (b) Mutant wio. The cortex has an unusual striated appearance and the coat layers have not developed so as to surround the whole spore. (c) Mutant DG47. The coat layers seem complete, but the cortex is not fully developed and much detail of the spore core remains visible. Electron micrographs of oligosporogenous mutants of Bacillus subtilis I68, showing cells which did not form mature spores. Bar markers represent $0.2 \mu \mathrm{m}$. 
revealed all the stages of sporulation in roughly similar proportions, instead of one stage predominating as was found with the wild-type and with other mutants examined. This type of mutant was therefore considered to be retarded rather than truly oligosporogenous.

Random sporulation. Previous work (Dawes, Kay \& Mandelstam, 197I) indicated that adjacent sister cells in a population of wild-type Bacillus subtilis I 68 undergoing sporulation generally behaved identically even though initiation to the process in the population as a whole appeared to be a random event. Examination in the electron microscope at defined times after initiation revealed that in $90 \%$ of the cell-pairs examined both cells had reached the same stage of development. This was explained by the observation that cells transferred to a resuspension medium underwent one cell division before beginning the sporulation process. The authors proposed that the initiation event is a random event in the mother cell and that the process then continues synchronously in both daughter cells.

In Osp mutants which produced an easily observable number of spores it was observed in the light microscope that cell-pairs often exhibited one cell with a mature spore, while the other cell exhibited the mutant phenotype. This non-identical behaviour of sister cells in the Osp mutants seemed to differ obviously from the observations with the wild-type. Therefore pairs of cells in electron micrographs prepared from two mutants, PI 4 and ZI2, at $t_{7}$ after resuspension were examined. For PI4, I67 cell-pairs were examined and of these 131 pairs exhibited both cells at stage II. No pairs were found in which one cell had stopped at stage II (or had formed a spore), while the other had not been initiated at all. Of the remaining cell-pairs, 32 ( $19 \%$ ) had one cell at stage II, while in the other cell the block at stage II had been overcome and the development had reached stage V to VI (Fig. $4 d$ ). For $\mathrm{ZI2}$, in $2 \mathrm{I}$ out of the $\mathrm{I} 48$ cell-pairs examined ( $14 \%$ ) one cell had reached stage V to VI, while the other cell was blocked at stage $\mathrm{O}$ or $\mathrm{I}$, i.e. showed no characteristics of a sporulating cell.

Now if the ability of one cell of a pair to overcome the block was not influenced by its partner and so was a random event, then the probability of finding both cells of a pair at stage VI would be $(0.19)^{2}=0.036$ for PI4 and $(0.14)^{2}=0.02$ for ZI2. For PI4, four out of the I 67 pairs $(0.024)$ had both cells at stage VI and for ZI 2 , seven out of the I48 pairs (0.047) had both cells fully developed. Thus, in overcoming the genetic block, sister cells in the two Osp cultures behaved very nearly as random members of the population. This contrasts with the virtually identical behaviour of the majority of cell-pairs after initiation to the process in the wild-type. It suggests that the ability to overcome the genetic block in an Osp mutant is determined only when that stage in the process is reached and that, unlike initiation to the process, it is not dictated by an event which took place earlier in the mother cell.

Only Osp mutants with a spore incidence between ro and $30 \%$ were examined. This was because for mutants with a spore incidence lower than $10 \%$ an inordinate number of pairs would have had to be examined in order to find a sufficient number in which both sister cells had formed spores. Mutants with a spore incidence greater than $30 \%$ were not considered, because the number of pairs where both cells had formed spores approached the level in the wild-type.

Correlation of biochemical events with morphological changes in oligosporogenous mutants. For the reasons given by Waites et al. (1970) the biochemical markers chosen for investigation in the mutants were considered to be sporulation specific. In this investigation octanol resistance was included and the times at which the markers occur during sporulation of the wild-type are included in Fig. I.

The properties in resuspended cultures of the mutants discussed in the previous section are given in Table $\mathrm{r}$. It should be noted that the levels of the marker events in an Osp culture are due not only to the levels in the blocked cells, but also to the levels in those cells able to 

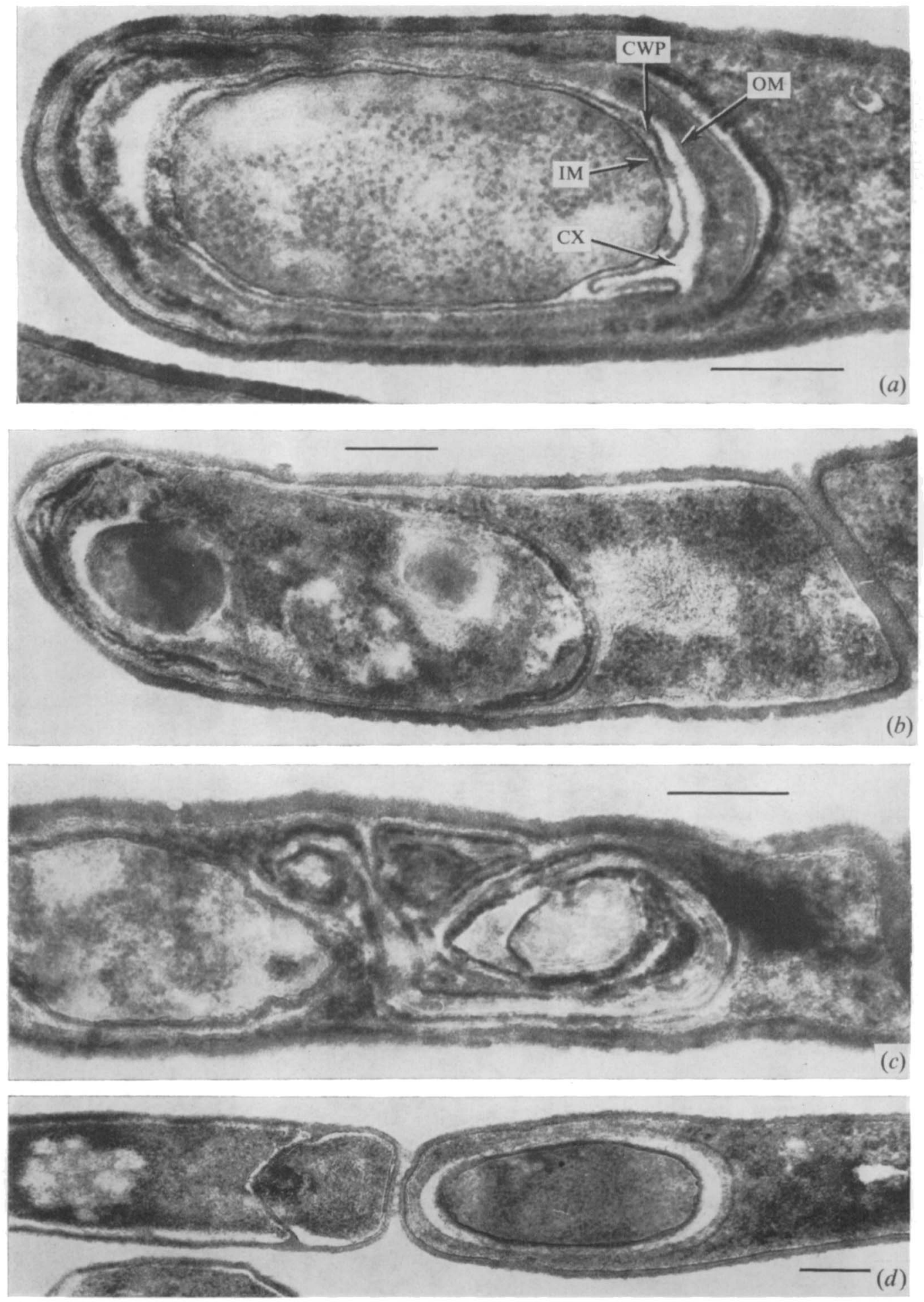
Table I. Comparison of sporulation marker events in samples removed from resuspended cultures of oligosporogenous mutants

Values were those obtained in resuspension experiments at $t_{7}$ except for alkaline phosphatase and glucose dehydrogenase which were the values at $t_{5}$. They are expressed as a percentage of the wild-type values which were taken as $100 \%$ in all cases. These were: alkaline phosphatase (60 units/ml of culture); glucose dehydrogenase (25.6 units $/ \mathrm{mg}$ protein); DPA $(5.3 \mu \mathrm{g} / \mathrm{ml}$ of culture); refractility ( $80 \%$ refractile spores); octanol resistance ( $80 \%$ resistant spores); and heat resistance (60\% resistant spores). The figures in brackets indicate poor refractility (grey appearance in the phase-contrast microscope).

\begin{tabular}{|c|c|c|c|c|c|c|c|c|}
\hline Strain & $\begin{array}{l}\text { Stage } \\
\text { blocked }\end{array}$ & Protease & $\begin{array}{l}\text { Alkaline } \\
\text { phosphatase }\end{array}$ & $\begin{array}{l}\text { Glucose de- } \\
\text { hydrogenase }\end{array}$ & Refractility & DPA & $\begin{array}{l}\text { Octanol } \\
\text { resistance }\end{array}$ & $\begin{array}{l}\text { Heat } \\
\text { resistance }\end{array}$ \\
\hline YI3 & $O \& I$ & - & $5 \cdot 0$ & $3 \cdot 0$ & $<\mathbf{I} \cdot 0$ & $<\mathrm{I} \cdot \mathrm{O}$ & $0 . I$ & 0.06 \\
\hline PIO & 0 \& I & + & $2 \cdot 0$ & $I \cdot O$ & $<\mathrm{I} \cdot \mathrm{O}$ & $<\mathrm{I} \cdot \mathrm{O}$ & 0.001 & 0.0005 \\
\hline PI 2 & $O \& I$ & + & $2 \cdot 0$ & $I \cdot 5$ & $<\mathrm{I} \cdot 0$ & $<\mathrm{I} \cdot \mathrm{O}$ & 0.001 & 0.001 \\
\hline Z3I & O \& I & + & $14 \cdot 0$ & $2 \cdot 5$ & $I \cdot O$ & $I \cdot O$ & 0.75 & 0.75 \\
\hline $\mathrm{ZI2}$ & $O \& I$ & + & $20 \cdot 0$ & $2 I \cdot 0$ & $15^{\circ} 0$ & $\mathrm{I} 2 \cdot 0$ & $14 \cdot 0$ & $13 \cdot 0$ \\
\hline Z29 & $O \& I$ & + & $2 \cdot 0$ & $I \cdot O$ & $<\mathrm{I} \cdot \mathrm{O}$ & $<\mathrm{I} \cdot \mathrm{O}$ & 0.01 & 0.01 \\
\hline P2 & 0 \& I & + & $42 \cdot 0$ & $28 \cdot 0$ & $30 \cdot 0$ & $22 \cdot 0$ & $20 \cdot 0$ & 20.0 \\
\hline PI3 & $O \& I$ & + & $28 \cdot 0$ & 20.5 & $20 \cdot 0$ & $18 \cdot 0$ & $15 \cdot 0$ & $12 \cdot 0$ \\
\hline PI9 & O \& I & + & $44^{\circ} 0$ & $27 \cdot 5$ & $30 \cdot 0$ & $25 \cdot 0$ & $25 \cdot 0$ & $23 \cdot 0$ \\
\hline PI4 & II & + & $23 \cdot 0$ & 19.0 & $20 \cdot 0$ & 17.0 & $21 \cdot 0$ & $20 \cdot 0$ \\
\hline PI 8 & II & + & $3 \cdot 0$ & I. 5 & $<\mathrm{I} \cdot \mathrm{O}$ & $<\mathrm{I} \cdot \mathrm{O}$ & 0.005 & 0.005 \\
\hline z3 & II & + & 85.0 & $3 \cdot 0$ & $5 \cdot 0$ & $5 \cdot 0$ & $6 \cdot 0$ & 50 \\
\hline P9 & II to III & + & $70 \cdot 0$ & I I 0 & $<\mathrm{I} \cdot \mathrm{O}$ & $<\mathbf{I} \cdot 0$ & 0.01 & 0.008 \\
\hline$x_{3}$ & III & + & $93 \cdot 0$ & $I \cdot 5$ & $I \cdot O$ & $1 \cdot 0$ & $I \cdot O$ & $I \cdot 0$ \\
\hline Y1O & III & + & 25.0 & $24{ }^{\circ} 0$ & $<\mathrm{I} \cdot \mathrm{O}$ & $<\mathrm{I} \cdot \mathrm{O}$ & 0.03 & 0.03 \\
\hline WI 2 & III & + & 85.0 & $45 \cdot 5$ & $<\mathrm{I} \cdot \mathrm{O}$ & $<\mathrm{I} \cdot \mathrm{O}$ & 0.001 & 0.001 \\
\hline Y9 & III & + & $73 \cdot 0$ & $52 \cdot 0$ & $<\mathrm{I} \cdot \mathrm{O}$ & $<\mathrm{I} \cdot \mathrm{O}$ & 0.005 & 0.004 \\
\hline $\mathbf{P} 4$ & III & + & 53.0 & $55 \cdot 5$ & $<\mathrm{I} \cdot \mathrm{O}$ & $<\mathrm{I} \cdot \mathrm{O}$ & 0.015 & 0.012 \\
\hline P7 & IV & + & $32 \cdot 0$ & $21 \cdot 5$ & $<\mathrm{I} \cdot \mathrm{O}(20)$ & $<\mathrm{I} \cdot \mathrm{O}$ & 0.025 & 0.02 \\
\hline Z24 & IV & + & $92 \cdot 0$ & 70.0 & $<\mathrm{I} \cdot \mathrm{O}(50)$ & $<\mathrm{I} \cdot \mathrm{O}$ & 0.5 & 0.5 \\
\hline Z33A & IV & + & $55^{\circ} 0$ & $62 \cdot 5$ & $I \cdot 0(30)$ & $I \cdot O$ & $I \cdot 0$ & $I \cdot O$ \\
\hline Z28 & IV & + & $82 \cdot 0$ & $8 I \cdot 0$ & $<\mathrm{I} \cdot \mathrm{O}(50)$ & $<\mathrm{r} \cdot \mathrm{O}$ & 0.1 & 0.1 \\
\hline $\mathrm{z5}$ & IV & + & $90 \cdot 0$ & $84 \cdot 0$ & $<\mathrm{I} \cdot \mathrm{O}(70)$ & $<\mathrm{r} \cdot \mathrm{O}$ & 0.2 & $0 \cdot 2$ \\
\hline $\mathrm{x} 8$ & IV & + & 83.0 & 80.5 & $1 \cdot 0(70)$ & $I \cdot 0$ & $I \cdot O$ & $I \cdot 0$ \\
\hline wro & V & + & $87 \cdot 0$ & $84 \cdot 5$ & $<\mathrm{I} \cdot \mathrm{O}(50)$ & $52 \cdot 0$ & 0.0001 & 0.0001 \\
\hline ZIOA & V & + & $42 \cdot 0$ & 35.5 & $I \cdot O(20$ & $I \cdot O$ & 0.8 & 0.55 \\
\hline DG47 & V & + & $86 \cdot 0$ & 65.0 & $<\mathrm{I} \cdot 0(50)$ & $<\mathrm{I} \cdot \mathrm{O}$ & $34 \cdot 0$ & 0.005 \\
\hline w5 & Abnormal & + & $85^{\circ} 0$ & 69.0 & $<\mathrm{I} \cdot \mathrm{O}(60)$ & $<\mathrm{I} \cdot \mathrm{O}$ & 0.001 & 0.001 \\
\hline WII & Abnormal & + & $80 \cdot 0$ & $94 \cdot 0$ & $50 \cdot 0$ & $45^{\circ} 0$ & $54^{\circ} 0$ & $52 \cdot 0$ \\
\hline P2O & Abnormal & + & $78 \cdot 0$ & $58 \cdot 5$ & $<\mathrm{I} \cdot \mathrm{O}(40)$ & $<\mathbf{I} \cdot 0$ & 0.17 & 0.15 \\
\hline
\end{tabular}

form heat-resistant spores. Thus in an Osp mutant with a $10 \%$ incidence of spores and a major block at say, $t_{3}$, one would expect normal values for exoprotease and alkaline phosphatase, but for glucose dehydrogenase and later events the expected values would be only 10 \% of the normal. The ability of the mutants to form heat-resistant spores varied from about $40 \%$ of the cells in mutant WII down to $0.0001 \%$ in mutant wio. Oligosporogenous mutants forming mature spores at even lower levels have been described (Bott \& Davidoff-

Fig. 4. (a) Mutant w5. The spore coat layers are well developed, but the cortex has not formed so as to occupy completely the space between the protoplast and the coat layers. Symbols: OM, outer spore membrane; IM, inner spore membrane; CWP, cell wall primordium; CX, cortex. (b) Mutant WII. The coat layers are again well formed, but the spore core is irregular and there is no obvious cortex development. (c) Mutant P2O. Development proceeds normally as far as the first stage of cortex formation, but the coat layers are laid down in the mother cell cytoplasm instead of around the protoplast. (d) Mutant PI4. A pair of cells showing normal development in one cell while that of the other cell has stopped at the spore septum stage. Electron micrographs of oligosporogenous mutants of Bacillus subtillis 168 , showing cells which did not form mature spores. Bar markers represent $0.2 \mu \mathrm{m}$. 
Abelson, 1966). However, in this investigation mutants with an incidence of spores lower than about one in $10^{6}$ cells were disregarded because these low numbers were not easily detectable with the assay procedure and also because the results were likely to be affected by back-mutation.

Of the mutants blocked at stages $O$ and $I$, all except YI 3 produced exoprotease in resuspension cultures, but the production of exoprotease by mutants ZI2, P2, PI3 and PI9 could have been due to that fraction of the population (relatively high in these mutants) which overcame the block and continued the sporulation process. This is more clearly demonstrated for alkaline phosphatase and glucose dehydrogenase for which the levels produced are roughly proportional to the final heat resistance. It is worth noting at this point that all except YI 3 and PIO of the mutants listed in Table I possessed the ability to produce antibiotic activity when assayed on nutrient agar plates inoculated with Staphylococcus aureus 524 as test organism (Brownlee et al. 1948). This marker is not included in Table I as antibiotic activity was not measured in samples of supernatants from resuspension experiments.

The mutants blocked at stage II produced exoprotease as expected, but only two ( 33 and P9) produced levels of phosphatase which approached those of the wild-type. All except P9 were negative for later events in the fraction of cells not forming spores. Mutant P9 produced glucose dehydrogenase which, although at a low level, was still well above the amount expected from the heat-resistant fraction of the population. All the mutants blocked at stage III produced exoprotease and high levels of phosphatase and all but one (x3) had high glucose dehydrogenase activity. The phosphatase and dehydrogenase activities in mutant YIO were only $25 \%$ of the wild-type activities and this may have reflected a lower incidence of initiation to sporulation as well as a block at stage III. The mutants blocked at stage IV formed feebly refractile (phase-grey) prespores and all but P7 had high levels of all the markers up to and including glucose dehydrogenase. The phosphatase and dehydrogenase activities in $\mathrm{P7}$ paralleled the percentage refractility and again probably reflected a lower occurrence of initiation to the process. The DPA values in all cases were equivalent to the final heat resistance.

Of the mutants that were blocked at stage V, wio produced $50 \%$ of the wild-type level of DPA, yet its final heat resistance was only 0.0001 \%. Approximately half of the DPA produced by this mutant was retained by the cells and half was lost to the surrounding medium. For mutant ZIOA the quantitative values for all the markers were again low compared with the wild-type, but the DPA content of this mutant paralleled the final heat resistance. Mutant DG47 produced about $30 \%$ octanol-resistant spores, yet they were DPA negative and had a very low level of heat resistance. The DPA values and octanol resistance of the morphologically abnormal mutants, W5, WI I and P2O, were equivalent to the final heat resistance. For all these mutants the values for earlier markers than DPA were similar to those in the wild-type.

\section{DISCUSSION}

The mutants investigated were chosen to exclude, as far as possible, any which were unable to grow as well as the wild-type under a variety of conditions. In this way it was hoped to confine the investigation to mutants blocked in functions specifically concerned with sporulation and to exclude mutants damaged in those vegetative functions that might also affect sporulation.

All of the mutants described here seem to have a majority of cells which get to a particular stage in the process and then stop. A few cells, the number depending on the individual mutant, then overcome the block successfully and go on to form heat-resistant spores. 
Mature spores from mutants examined in the electron microscope appeared quite normal. Except for one slowly sporulating strain, the number of heat-resistant spores in resuspension cultures at $t_{7}$ to $t_{8}$ was almost equal to the number finally obtained. A class of Osp mutants has been described (Balassa \& Yamamoto, 1970) which at $t_{8}$ demonstrated all the stages of sporulation. The authors suggested that these might be a separate class of regulatory mutants which have increasing difficulty in passing each successive stage so that finally only a few cells yield heat-resistant spores. No representative of this type of mutant was found during this investigation and there is the possibility that these represent mutants damaged in some vegetative function, such as the generation of ATP which might be needed in large amounts at several stages. The slowly sporulating mutant that is described in this paper demonstrated all the stages of sporulation at $t_{7}$, but eventually formed as many spores as the wild-type.

In the Osp mutants examined here it is clear that, as in $\mathrm{Sp}^{-}$mutants, the developmental sequence may be arrested at defined points during the process. Many of the mutants, especially those blocked between stages $\mathrm{O}$ to $\mathrm{IV}$, have $\mathrm{Sp}^{-}$counterparts which have been previously described. This is consistent with the idea that many Osp mutations are leaky forms of $\mathrm{Sp}^{-}$mutations. Others present new features and this may indicate a real difference between the Osp and $\mathrm{Sp}^{-}$characters, for instance that there are separate classes of Osp and $\mathrm{Sp}^{-}$regulatory mutations, or alternatively it might reflect the fact that not enough mutants of both types have been examined.

The marker events used (Table I) occurred to an extent which was consistent with the stage at which the bulk of the cells in any one mutant were blocked and with the degree of oligosporogeny. Thus mutants blocked at stage $\mathrm{O}$ or I may or may not have produced exoprotease, but the activity of alkaline phosphatase in most instances was consistent with the final heat resistance. Of the stage II mutants, two ( $\mathrm{z} 3$ and $\mathrm{P} 9$ ) produced phosphatase in excess of what would be expected on the basis of heat resistance and both mutants exhibited bulging of the spore septum into the mother cell cytoplasm. Stage III mutants, like their $\mathrm{Sp}^{-}$counterparts (Waites et al. 1970), all produced phosphatase in excess of the number of heat-resistant spores and five of the six also had high glucose dehydrogenase activities. This latter enzyme may be associated with formation of the protoplast, but is synthesized later than the phosphatase. The feeble refractility exhibited by most cells of the stage IV mutants was associated with formation of the cortex. It was achieved even though the cells lacked the ability to synthesize DPA, the amount of which in all cases was proportional to the final heat-resistance. One stage V mutant (wIO) produced DPA to $50 \%$ of the wild-type level, yet the spores were mainly octanol- and heat-sensitive. This fact seems to rule out DPA by itself as being responsible for either octanol of heat resistance. Another stage V mutant (DG47) produced octanol-resistant, but mainly heat-sensitive and DPA-negative spores. In Bacillus subtilis the development of octanol resistance precedes heat resistance by about $\mathrm{I} h$ and has been associated with formation of the coat layers (Ryter, 1965), yet mutants ZIOA and w5 produced octanol-sensitive spores which had well-developed coat layers. This indicates that octanol resistance requires more than just the presence of the coat material, but at the same time seems not to be dependent on the presence of DPA.

Most values for the marker events in all the Osp mutants were consistently below those obtained with the wild-type and this probably reflected a poorer initiation to the sporulation process in the mutants. However, the correlation found between the marker events and the morphological changes is similar to that found previously in the wild-type and $\mathrm{Sp}^{-}$mutants (Waites et al. 1970). The results substantiate the idea of a dependent sequence of biochemical and morphological changes where the occurrence of any one event depends on the successful completion of earlier events. The only exceptions to this were mutants which had well- 
developed coat layers, but in which the cortex was only poorly formed or completely missing (W5, WII and P20). The sporulation pathway may therefore branch at the point of cortex formation.

A working hypothesis for sporulation is that it is controlled by several operons which are expressed in a definite order, being induced in a sequential manner. An Osp mutant can be viewed as having a leaky mutation in a structural gene (i.e. the gene produces normal amounts of slightly active enzyme or small quantities of fully active enzyme), so that in a given culture only a certain proportion of cells achieve a threshold level of enzyme activity sufficient to continue the process. Alternatively, a regulatory gene affecting a repressor or an inducer might have mutated in such a way that in only a few cells could transcription of spore genes occur. Whatever explanation is adopted the concept of a threshold level seems necessary to explain why only a fraction of genetically homogeneous cells are able to overcome the block and continue the process. It is conceivable that this threshold level can be affected by the environment and may explain why some Osp mutants have a variable incidence of spore formation when grown and allowed to sporulate with different carbon sources.

The observations on cell-pairs of mutant PI4 substantiate the idea that initiation to the sporulation process is determined before final cell division takes place (Dawes et al. 1971) because no pairs were seen where one cell was initiated and the other not. When comparing cell-pairs of both mutants PI4 and ZI 2 for the ability to overcome the block and form heatresistant spores this was no longer true. It was found that if one cell of a pair had formed a spore the probability was that the other had not. This suggests that the ability to overcome the mutation is not predetermined in the same way as initiation, but takes place when that stage in the process is reached. This presumably reflects physiological variability between cells in a culture so that a cell may randomly produce just sufficient of the limiting activity to overcome the block.

The evidence presented here indicates a very similar pattern of morphological and biochemical behaviour between Osp mutants and $\mathrm{Sp}^{-}$mutants previously described. Although there is still the possibility that some Osp mutants are of a distinct regulatory type, in many instances the Osp and $\mathrm{Sp}^{-}$states are so similar phenotypically that it seems reasonable to suppose that they are alternative expressions of mutation within a single gene. This is given additional support by genetic evidence presented elsewhere (Coote, 1972).

I am very grateful to Professor J. Mandelstam for valuable advice and criticism. I am indebted to Dr D. Kay for advice on electron microscopic procedures and to Mrs Dawn Torgerson for skilled technical assistance. The work was supported by a grant from the Science Research Council.

\section{REFERENCES}

Aubert, J. P. \& Millet, J. (1961). Influence de l'alimentation carbonée sur le taux de sporulation de mutants de sporulation de Bacillus megaterium. Compte rendu hebdomadaire des séances de l'Academie des sciences 253, I880-1882.

Balassa, G. \& YAMAMOTo, T. (1970). Biochemical genetics of bacterial sporulation. III. Correlation between morphological and biochemical properties of sporulation mutants. Molecular and General Genetics ro8, I-22.

Bott, K. F. \& Davidoff-Abelson, R. (1966). Altered sporulation and respiratory patterns in mutants of Bacillus subtilis induced by acridine orange. Journal of Bacteriology 92, 229-240.

Brownlee, K. A., Delves, C. S., Dorman, M., Green, C. A., Grenfell, E., Johnson, J. D. A. \& Smith, N. (I948). The biological assay of streptomycin by a modified cylinder plate method. Journal of General Microbiology 2, 40-53.

Coote, J. G. (1972). Sporulation in Bacillus subtilis. Genetic analysis of oligosporogenous mutants. Journal of General Microbiology 7x, 17-27. 
Dawes, I. W., Kay, D. \& Mandelstam, J. (1969). Sporulation in Bacillus subtilis. Establishment of a time scale for the morphological events. Journal of General Microbiology 56, I 7 I-1 79.

Dawes, I. W., KaY, D. \& Mandelstam, J. (I97I). Determining effect of growth medium on the shape and position of daughter chromosomes and on sporulation in Bacillus subtilis. Nature, London 230, 567-569.

Fortnagel, P. \& Freese, E. (1968). Analysis of sporulation mutants. II. Mutants blocked in the citric acid cycle. Journal of Bacteriology 95, I43 I-I438.

Hanson, R. S., Blicharska, J. \& Szulmajster, J. (1964). Relationship between the tricarboxylic acid cycle enzymes and sporulation in Bacillus subtilis. Biochemical and Biophysical Research Communications I7, $\mathbf{I}-7$.

Hanson, R. S. \& Mackechnie, I. (I969). Regulation of sporulation and the entry of carbon into the tricarboxylic acid cycle. In Spores, vol. IV, pp. I96-2 I I. Edited by L. L. Campbell. Bethesda, Maryland: American Society for Microbiology.

Hanson, R. S., Peterson, J. A. \& Yousten, A. A. (1970). Unique biochemical events in bacterial sporulation. Annual Review of Microbiology 24, 53-90.

IICHINSKA, E. (I960). Some physiological features of asporogenous mutants of bacilli. (English translation.) Microbiology (U.S.S.R.) 29, I47-I 50.

KAY, D. \& WARren, S. C. (1968). Sporulation in Bacillus subtilis. Morphological changes. Biochemical Journal ro9, 819-824.

Kornberg, A., Spudich, J. A., Nelson, D. L. \& Deutscher, M. P. (i968). Origin of proteins in sporulation. Annual Review of Biochemistry 37, 5I-78.

Lowry, O. H., Rosebrough, N. J., Farr, A. L. \& Randall, R. J. (I95I). Protein measurement with the Folin phenol reagent. Journal of Biological Chemistry 193, 265-275.

Mandelstam, J. (1969). Regulation of bacterial spore formation. Symposium of the Society for General Microbiology 19, 377-402.

Mandelstam, J. \& Waites, W. M. (1968). Sporulation in Bacillus subtilis. The role of exo-protease. Biochemical Journal ro9, 793-80I.

Murrell, W. G. (1967). The biochemistry of the bacterial endospore. Advances in Microbial Physiology I, I33-25I.

RYTER, A. (1965). Étude morphologique de la sporulation de Bacillus subtilis. Annales de l'Institut Pasteur I08, 40-60.

Ryter, A., Schaeffer, P. \& Ionesco, H. (1966). Classification cytologique, par leur stade de blocage, des mutants de sporulation de Bacillus subtilis marbURG. Annales de l'Institut Pasteur 110, 305-315.

SCHAEFFER, P. (1969). Sporulation and the production of antibiotics, exoenzymes and exotoxins. Bacteriological Reviews 33, 48-71.

SchaEfFER, P. \& IONESCO, H. (1960). Contribution à l'étude génétique de la sporogenèse bactérienne, Compte rendu hebdomadaire des séances de l'Academie des sciences 25I, 3I 25 -3 I 27.

Schaeffer, P., Ionesco, H., Ryter, A. \& Balassa, G. (1965). La sporulation de Bacillus subtilis: étude génétique et physiologique. Colloques internationaux du centre national de la recherche scientifique $\mathbf{1 2 4}$, $553-563$.

Sterlini, J. M. \& Mandelstam, J. (I969). Commitment to sporulation in Bacillus subtilis and its relationship to development of actinomycin resistance. Biochemical Journal 113, 29-37.

Waites, W. M., Kay, D., Dawes, I. W., Wood, D. A., Warren, S. C. \& Mandelstam, J. (i970). Sporulation in Bacillus subtilis. Correlation of biochemical events with morphological changes in asporogenous mutants. Biochemical Journal $\mathbf{1} 8,667-676$.

WARREN, S. C. (1968). Sporulation in Bacillus subtilis. Biochemical changes. Biochemical Journal ro9, 81 I-81 8. 